\title{
Risk factors for hepatic veno-occlusive disease caused by Gynura segetum: a retrospective study
}

\author{
Yan Wang ${ }^{1}$, Dan Qiao $^{2}$, Ya Li $^{1}$ and Feng $\mathrm{Xu}^{1 *}$
}

\begin{abstract}
Background: Hepatic veno-occlusive disease (HVOD) caused by Gynura segetum has been increasingly reported in China in recent years. The aim of this retrospective study was to identify independent prognostic markers for survival in patients with Gynura segetum-induced HVOD and to evaluate the effect of anticoagulants and transjugular intrahepatic portosystemic shunt (TIPS) on survival rate.

Methods: Clinical data including symptoms, signs, imaging characteristics, laboratory test results, results of liver tissue biopsies, type of treatment during follow-up and clinical outcomes were collected. Univariate, multivariate and timedependent Cox regression analyses were performed.

Results: Survival rates were 91\% (95\% confidence interval [Cl], 82-95\%), 64\% (95\% Cl, 53-69\%) and 57\% (95\% Cl, 51$65 \%$ ) at 1, 3 and 60 months, respectively. Total bilirubin, albumin and hepatic encephalopathy were independent prognostic markers of survival. Anticoagulants were administered to $76 \%$ of the patients. Among 75 patients treated with anticoagulants, 49 patients (65.3\%) were cured, whereas 26 patients (34.7\%) died; the cure rate in anticoagulanttreated patients was higher than that of those not treated with anticoagulants $\left(X^{2}=9.129, P=0.004\right)$. Cure rate of the anticoagulation + TIPS treatment group was $64.3 \%$, which was also higher than that of the non-anticoagulation group; however, this was not significantly different $\left(X^{2}=3.938, P=0.096\right)$.

Conclusions: The presence of hepatic encephalopathy, serum bilirubin and albumin levels were major prognostic factors for Gynura segetum-induced HVOD. Anticoagulation therapy significantly increased the cure rate; however, TIPS treatment did not have a beneficial effect on the cure rate.
\end{abstract}

Keywords: Hepatic veno-occlusive disease, Gynura segetum, Anticoagulant, Transjugular intrahepatic portosystemic shunt, Prognostic factor

\section{Background}

Hepatic veno-occlusive disease (HVOD), also termed hepatic sinusoidal obstruction syndrome, is a rare clinical syndrome caused by several factors including high-dose chemotherapy before haematopoietic stem cell transplantation (HSCT) [1, 2], high-dose chemotherapy and ingestion of herbal compounds containing pyrrolizidine alkaloids (PAs) [3]. In China, HVOD has rarely been reported in patients who received HSCT despite the large number of HSCT cases. HVOD caused by Gynura

\footnotetext{
*Correspondence: doctorxuyfy@163.com

'Department of Gastroenterology, The First Affiliated Hospital of Zhengzhou

University, 1 Jianshe Donglu, Zhengzhou 450052, Henan, China

Full list of author information is available at the end of the article
}

segetum (i.e. Tusanqi)-containing PAs, a Chinese medicinal herb used for self-medication as well as pain relief, hypertension and dissipation of blood stasis [4], has been increasingly reported in China in recent years [5-7].

HVOD is defined as intrahepatic post-sinusoidal portal hypertension caused by stenosis or occlusion of veins, including the central veins of hepatic lobules and the sublobular veins [8]. HVOD is associated with significant mortality due to the severity of the disease and the absence of uniformly effective therapies. Until recently, treatment approaches have largely involved supportive and symptomatic care, such as restriction of water and sodium intake, diuretics, paracentesis and albumin infusion. Other treatment options include anticoagulant

(C) The Author(s). 2018 Open Access This article is distributed under the terms of the Creative Commons Attribution 4.0 International License (http://creativecommons.org/licenses/by/4.0/), which permits unrestricted use, distribution, and 
therapy, transjugular intrahepatic portosystemic shunt (TIPS) [9] and liver transplantation [10].

HSCT-related HVOD differs from that associated with Gynura segetum in many aspects, such as aetiology, ethnicity, underlying diseases, clinical findings and treatment. Not much is known about factors that might be relevant in predicting survival in patients with Gynura segetum-related HVOD. Most studies are case reports or include limited numbers of patients because of the rarity of this clinical presentation. The aim of this retrospective study was to identify independent prognostic markers for survival in patients with Gynura segetum-induced HVOD and to evaluate the effect of anticoagulants and TIPS on survival.

\section{Methods}

\section{Patients and database}

Between July 2012 and July 2017, 132 patients admitted to the First Affiliated Hospital of Zhengzhou University with a clinical diagnosis of HVOD and stated to have ingested Gynura segetum were included in this retrospective study. Previously described diagnostic criteria for Tusanqiinduced HVOD was used [11-13]. Patients with the following conditions were excluded from the study: chronic liver disease due to other causes, hepatocellular carcinoma, Budd-Chiari syndrome, congestive heart disease and incomplete data.

This study was approved by the Ethics Committee of the First Affiliated Hospital of Zhengzhou University in Zhengzhou, China. Written informed consent to participate was obtained from all patients. In all cases, the first available data were used as baseline data. Clinical data including symptoms, signs, imaging characteristics, laboratory test results, results of liver tissue biopsies, types of treatment during follow-up and clinical outcomes were collected. All patients were followed up from the date of diagnosis until death, lost to follow-up or study closure on 31 July 2017.

\section{Treatment}

Patients who received treatments other than anticoagulants, such as diuretics, paracentesis, albumin and/or liver unction protection, were categorised in the nonanticoagulation group. After exclusion of contraindications, anticoagulation therapy was administered as follows: oral warfarin at $1.5 \mathrm{mg}$ daily, with dose adjustment to maintain an international normalised ratio between 2 and 3, combined with low-molecular-weight heparin at 4000 IU by subcutaneous injection every $12 \mathrm{~h}$. In patients whose symptoms improved, anticoagulation therapy was maintained until complete remission. In patients whose symptoms did not improve or worsened after 2 weeks of anticoagulation therapy, TIPS was performed following assessment of the patient.

\section{Statistical analysis}

All statistical analyses were performed using SPSS statistical software version 17.0 (SPSS, Chicago, Illinois, USA). All continuous variables were expressed as medians (25th75th percentiles) and compared with Student's $t$ test or non-parametric test according to the distribution characteristics. Categorical variables were expressed as numbers with percentages and compared by the $\chi^{2}$ test or Fisher's exact

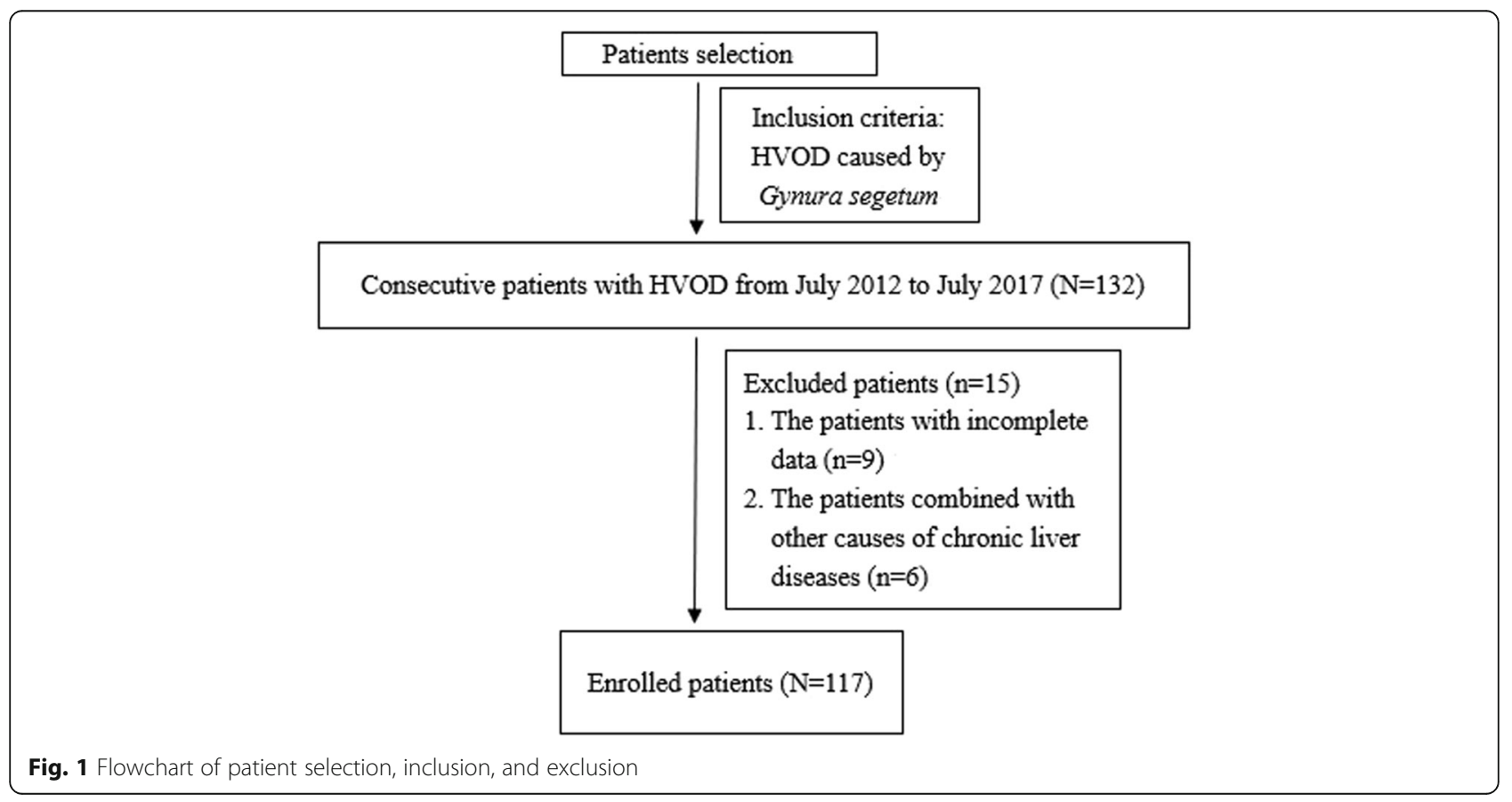


test. Survival rates were calculated using the Kaplan-Meier method. Univariate survival analysis to assess the effect of patient characteristics was based on comparison of survival curves by the log-rank test. Statistically significant variables were introduced into a multivariate Cox's proportional hazards analysis. A $P$ value less than 0.05 was considered to indicate a significant difference.

\section{Results}

\section{Patient characteristics}

After the exclusion of 15 patients who did not fulfil the inclusion criteria, a total of 117 patients who were eligible were included in the analysis (Fig. 1). Patient characteristics at the time of diagnosis are presented in Table 1. Median age was 63 years (range, 18-84 years), and $67 \%$ of the patients were male. The most common clinical presentation was ascites (99.1\%), followed by abdominal distention (98.3\%), hepatomegaly (70\%), poor appetite (41\%), lower limb oedema (39.3\%), splenomegaly $(34.2 \%)$ and malaise (33.3\%).

\section{Survival}

In this study, follow-up period ranged from 3 days to 60 months. During the follow-up, 50 patients (43\%) died, and causes of death were liver failure $(n=19)$, postoperative multiorgan failure $(n=2)$, cardiovascular disease $(n=$ $3)$, variceal bleeding $(n=3)$, sepsis $(n=3)$, newly developed malignancy $(n=5)$ and combinations of causes $(n=9)$. Information on cause of death could not be retrieved for six patients. Survival rates were 91\% (95\% confidence interval [CI], 82-95\%), 64\% (95\% CI, 53-69\%) and 57\% (95\% CI, 51-65\%) at 1, 3 and 60 months, respectively (Fig. 2).

\section{Prognostic factors}

Univariate analysis revealed that hepatic encephalopathy $(P=0.005)$, total bilirubin $(P<0.001)$, direct bilirubin $(P$ $=0.001)$, albumin $(P=0.044)$, blood urea nitrogen $(P=$ $0.022)$ and treatment $(P=0.009)$ were significantly associated with survival (Table 2).

These variables as well as age, sex and platelet count were introduced into a multivariate Cox regression model. Variables were selected using a forward and backward elimination procedure with a significance level of 0.10. The final Cox model showed that total bilirubin $(P=0.004)$, albumin $(P=0.024)$ and hepatic encephalopathy $(P=0.018)$ were independent prognostic markers for survival in this cohort of 117 patients who had complete data for these variables (Table 3).

\section{Interventions}

In this study, 28 of the 117 patients (24\%) were managed medically with supportive and diuretic therapeutic approaches such as diuretics, paracentesis, albumin and/or liver function protection only for control of ascites.
Table 1 Characteristics of 117 patients with hepatic venoocclusive disease at the time of diagnosis

\begin{tabular}{|c|c|}
\hline Characteristic & Obtained data \\
\hline Age (years) & $63.0(52.5-69.0)$ \\
\hline Male/female (\%) & $67 / 33$ \\
\hline \multicolumn{2}{|l|}{ Clinical manifestations, n (\%) } \\
\hline Ascites & $116(99.1)$ \\
\hline Abdominal distention & $115(98.3)$ \\
\hline Poor appetite & $48(41.0)$ \\
\hline Nausea, vomiting & $19(16.2)$ \\
\hline Malaise & $39(33.3)$ \\
\hline Lower limb oedema & $46(39.3)$ \\
\hline Hepatomegaly & $82(70.0)$ \\
\hline Splenomegaly & $40(34.2)$ \\
\hline Right upper quadrant pain & $23(19.7)$ \\
\hline Weight gain & $21(18.0)$ \\
\hline Encephalopathy & $19(16.2)$ \\
\hline Variceal bleeding & $3(2.6)$ \\
\hline \multicolumn{2}{|l|}{ Laboratory tests } \\
\hline WBC $\left(10^{9} / L\right)$ & $6.1(5.0-8.7)$ \\
\hline $\operatorname{RBC}\left(10^{12} / \mathrm{L}\right)$ & $4.4(3.9-4.9)$ \\
\hline $\operatorname{PLT}\left(10^{9} / \mathrm{L}\right)$ & $113(78-153)$ \\
\hline $\operatorname{ALT}(\mathrm{U} / \mathrm{L})$ & $49.0(25.0-152.5)$ \\
\hline AST (U/L) & $75.0(39.0-158.5)$ \\
\hline GGT $(U / L)$ & $100.7(61.8-164.8)$ \\
\hline $\mathrm{ALP}(\mathrm{U} / \mathrm{L})$ & 122.0 (86.8-191.3) \\
\hline TB $(\mu \mathrm{mol} / \mathrm{L})$ & $33.3(19.7-47.0)$ \\
\hline $\mathrm{DB}(\mu \mathrm{mol} / \mathrm{L})$ & $21.5(12.7-30.5)$ \\
\hline $\operatorname{ALB}(g / L)$ & $30.6(27.7-33.6)$ \\
\hline PT (s) & $14.8(12.7-17.0)$ \\
\hline BUN (mmol/L) & $5.5(3.8-7.9)$ \\
\hline$C R(\mu \mathrm{mol} / \mathrm{L})$ & $74.0(60.0-90.0)$ \\
\hline CA-125 (U/ml) & $259.9(182.1-458.4)$ \\
\hline CA199 & $13.04(7.9-34.2)$ \\
\hline \multicolumn{2}{|l|}{ Treatment, n (\%) } \\
\hline Non-anticoagulation & $26(22.2)$ \\
\hline Anticoagulation & $74(63.2)$ \\
\hline Anticoagulation + TIPS & $17(14.5)$ \\
\hline
\end{tabular}

WBC white blood cell count, $R B C$ red blood cell count, PLT platelet count, AST aspartate aminotransferase, $A L T$ alanine aminotransferase, GGT $\lambda$-glutamyl transferase, $A L P$ alkaline phosphatase, $T B$ total bilirubin, $D B$ direct bilirubin, $T P$ total protein, $A L B$ albumin, $B U N$ blood urea nitrogen, $C R$ creatinine, $P T$ prothrombin time, TIPS transjugular intrahepatic portosystemic shunt

Conversely, 89 patients of 117 (76\%) were treated with anticoagulants in addition to the above mentioned non-anticoagulation therapeutic approaches. None of the patients who were treated with anticoagulant therapy developed complications due to the combination of 


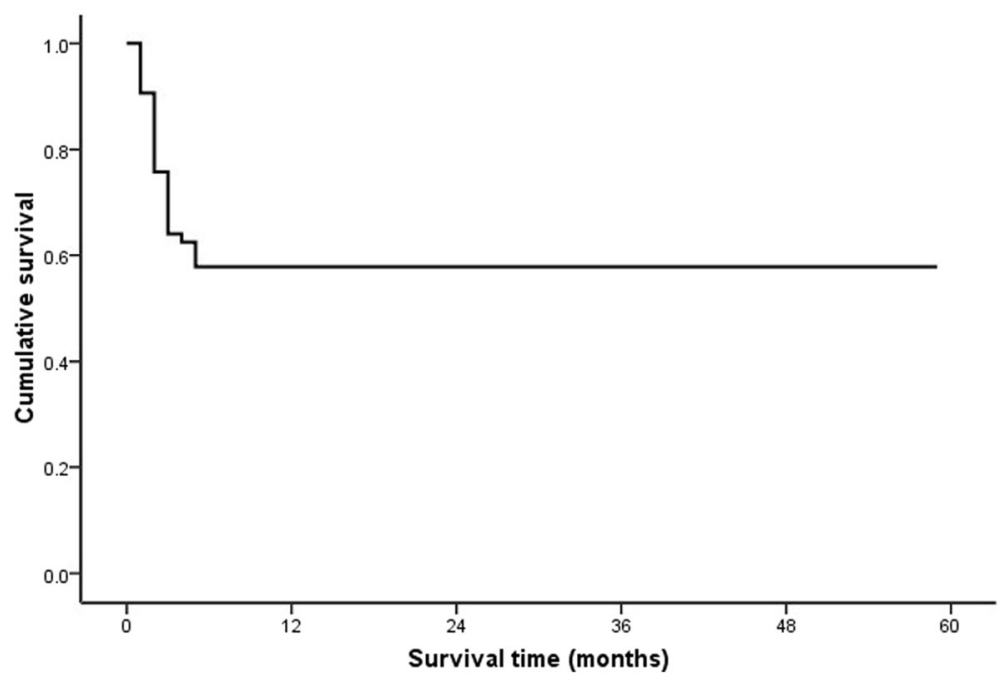

Fig. 2 Overall survival in 117 patients with hepatic veno-occlusive disease caused by Gynura segetum

warfarin and low-molecular-weight heparin, such as severe bleeding. TIPS was performed in 14 patients (12\%) during follow-up; five of the patients died because of complications or multiple organ failure. None of the patients received liver transplantation (Table 2).

\section{Benefit of anticoagulation and TIPS}

The use of anticoagulants to prevent thrombosis was found to yield a significant beneficial effect on survival in the current study cohort. Among 28 patients who received non-anticoagulation treatment, 9 (32.1\%) were cured, whereas 19 patients $(67.9 \%)$ died during treatment period. Among a total of 75 patients treated with anticoagulants, 49 patients $(65.3 \%)$ were cured and 26 patients $(34.7 \%)$ died (Table 4). The cure rate was higher in the anticoagulation group than in the non-anticoagulation group $\left(x^{2}=9.129, P\right.$ $=0.004)$. The cure rate in the anticoagulation + TIPS treatment group was $64.3 \%$, which was also higher than that in the non-anticoagulation group, albeit without a statistical significance $\left(x^{2}=3.938, P=0.096\right)$. Furthermore, there was no statistical difference in the cure rates between the anticoagulation group and anticoagulation + TIPS group $\left(X^{2}=0.006, P=1.00\right)$.

\section{Discussion}

HVOD, first described by Willmot and Robertson in 1920, is a clinical syndrome characterised by hepatomegaly, weight gain, ascites and jaundice [14, 15]. In Western countries, HVOD is most commonly associated with HSCT and high-dose chemotherapy [3, 16], whereas there is growing concern in developing countries over the use of Gynura segetum, which can also cause HVOD. Although hepatic impairment due to conventional pharmaceutical drug use is widely acknowledged, the potential hepatotoxicity of herbal preparations is underestimated because of the public misconception that they are harmless. Importantly, these herbal compounds are commonly used for self-medication without supervision.

Clinically, HVOD diagnosis is usually achieved on the basis of the criteria put forth by the Baltimore and Seattle groups $[2,17]$, which are based on clinical findings that include painful hepatomegaly, weight gain, hyperbilirubinemia and ascites [14]. The specificity of these two criteria is about 92\%; however, their sensitivity is relatively low [10].The current study showed that the most prominent clinical manifestations of Gynura segetum-induced HVOD were abdominal distention (98.3\%), ascites (99.1\%) and hepatomegaly $(70 \%)$, whereas only about half of the patients exhibited jaundice, and only $19.7 \%$ of the patients had right upper quadrant pain. These results are consistent with the previous studies [18]. Thus, the diagnosis in patients of the current study was based on the history of Gynura segetum intake, clinical manifestations, imaging results and pathological features. Histological assessment of liver biopsy specimen remains the gold standard for the diagnosis of HVOD; the pathology often includes expansion and congestion of the hepatic sinus, endothelial swelling, wall thickening and incomplete luminal occlusion of the hepatic vein [19]. However, liver biopsy is usually delayed because of extensive ascites, clotting abnormalities and thrombocytopaenia [10]. Recent studies showed that contrast-enhanced computed tomography and magnetic resonance imaging were effective noninvasive methods for the early diagnosis of Tusanqi-induced HVOD and could replace histological examination of the liver in patients with typical clinical data and imaging findings. Patchy enhancement, heterogeneous hypoattenuation in portal phase of the computed tomography or non-homogeneous signal by magnetic resonance imaging are main imaging signs of HVOD [6-8]. 
Table 2 Univariate analysis of risk factors associated with survival in 117 patients with hepatic veno-occlusive disease

\begin{tabular}{|c|c|c|c|c|}
\hline Variable & $\begin{array}{l}\text { Rehabilitation Group } \\
(n=67)\end{array}$ & $\begin{array}{l}\text { Death Group } \\
(n=50)\end{array}$ & Statistic & $P$ value \\
\hline Age (years) & $63.0(52.3-69.0)$ & $61.5(48.3-67.8)$ & $t=0.871$ & 0.385 \\
\hline Male/female (\%) & $67 / 33$ & $64 / 36$ & $x^{2}=0.008$ & 0.565 \\
\hline \multicolumn{5}{|l|}{ Clinical manifestations, n (\%) } \\
\hline Ascites & $67(100)$ & $49(98.0)$ & $x^{2}=1.352$ & 0.427 \\
\hline Abdominal distention & $66(98.5)$ & $49(98.0)$ & $x^{2}=0.044$ & 0.834 \\
\hline Poor appetite & $22(32.8)$ & $26(52.0)$ & $x^{2}=4.346$ & 0.057 \\
\hline Nausea, vomiting & $7(10.4)$ & $11(22.0)$ & $x^{2}=2.935$ & 0.120 \\
\hline Malaise & $22(32.8)$ & $17(34.0)$ & $x^{2}=0.895$ & 0.525 \\
\hline Lower limb oedema & $23(34.3)$ & $23(46.0)$ & $x^{2}=1.653$ & 0.252 \\
\hline Hepatomegaly & $45(67.2)$ & $37(74.0)$ & $x^{2}=0.638$ & 0.541 \\
\hline Splenomegaly & $22(32.8)$ & $18(36.0)$ & $x^{2}=0.127$ & 0.844 \\
\hline Right upper quadrant pain & $14(20.9)$ & $9(18.0)$ & $x^{2}=0.152$ & 0.815 \\
\hline Weight gain & $11(16.4)$ & $10(20.0)$ & $x^{2}=0.249$ & 0.634 \\
\hline Encephalopathy & $5(7.5)$ & $14(28.0)$ & $x^{2}=8.878$ & 0.005 \\
\hline Variceal bleeding & 0 & $3(6.0)$ & $x^{2}=4.126$ & 0.075 \\
\hline \multicolumn{5}{|l|}{ Laboratory tests } \\
\hline WBC $\left(10^{9} / L\right)$ & $6.1(5.4-9.3)$ & $6.4(4.5-8.6)$ & $t=0.171$ & 0.864 \\
\hline $\mathrm{RBC}\left(10^{12} / \mathrm{L}\right)$ & $4.4(4.0-4.8)$ & $4.4(3.3-5.1)$ & $Z=0.933$ & 0.349 \\
\hline $\operatorname{PLT}\left(10^{9} / \mathrm{L}\right)$ & $115.0(77.0-148.0)$ & $105(76-144)$ & $Z=0.676$ & 0.750 \\
\hline $\operatorname{ALT}(\mathrm{U} / \mathrm{L})$ & $69.0(25.0-201.0)$ & $38.0(23.0-86.0)$ & $Z=1.040$ & 0.230 \\
\hline AST (U/L) & $100.0(44.0-189.0)$ & $72.0(38.0-158.0)$ & $Z=0.902$ & 0.389 \\
\hline GGT (U/L) & $97.0(61.5-161.0)$ & 113.1 (49.8-176.6) & $Z=0.746$ & 0.635 \\
\hline $\mathrm{ALP}(\mathrm{U} / \mathrm{L})$ & $111.0(82.5-148.0)$ & $137.0(84.8-202.0)$ & $Z=1.002$ & 0.267 \\
\hline TB $(\mu \mathrm{mol} / \mathrm{L})$ & $26.7(19.7-36.4)$ & $43.75(37.0-83.0)$ & $Z=2.163$ & $<0.001$ \\
\hline $\mathrm{DB}(\mu \mathrm{mol} / \mathrm{L})$ & $15.1(12.8-26.1)$ & $27.9(21.6-59.4)$ & $Z=1.914$ & 0.001 \\
\hline ALB (g/L) & $30.6(28.9-34.4)$ & $29.8(27.1-32.5)$ & $t=2.052$ & 0.044 \\
\hline PT (s) & $14.8(12.4-16.5)$ & $15.2(13.1-18.5)$ & $t=-0.774$ & 0.442 \\
\hline BUN (mmol/L) & $5.0(3.8-6.3)$ & $7.0(3.6-9.51)$ & $Z=1.503$ & 0.022 \\
\hline$C R(\mu \mathrm{mol} / \mathrm{L})$ & $71.0(58.0-84.0)$ & $71.0(53.5-94.0)$ & $t=-0.088$ & 0.930 \\
\hline CA-125 (u/ml) & $224.5(136.6-430.7)$ & 270.1 (181.9-429.5) & $t=-0.083$ & 0.935 \\
\hline CA199 & $11.9(7.8-25.0)$ & $17.6(8.3-38.8)$ & $Z=0.672$ & 0.757 \\
\hline \multicolumn{5}{|l|}{ Treatment, n (\%) } \\
\hline Non-anticoagulation & $9(13.4)$ & $19(38.0)$ & $x^{2}=9.498$ & 0.009 \\
\hline Anticoagulation & $49(73.1)$ & $26(52.0)$ & & \\
\hline Anticoagulation + TIPS & $9(13.4)$ & $5(10.0)$ & & \\
\hline
\end{tabular}

Table 3 Results of the multivariate Cox regression analysis of 117 patients with hepatic veno-occlusive disease

\begin{tabular}{llll}
\hline Variable & $P$ value & Risk Ratio & $95 \% \mathrm{Cl}$ \\
\hline TB $(\mu \mathrm{mol} / \mathrm{L})$ & 0.004 & 1.006 & $1.002-1.010$ \\
ALB $(\mathrm{g} / \mathrm{L})$ & 0.024 & 0.932 & $0.816-1.063$ \\
Encephalopathy & 0.018 & & \\
Present & & 3.440 & $1.240-9.543$ \\
Absent & & & \\
\hline
\end{tabular}

Table 4 The effects of different treatment approaches on prognosis of patients with Gynura segetum-induced hepatic veno-occlusive disease

\begin{tabular}{|c|c|c|c|c|c|}
\hline \multirow[t]{2}{*}{ Group } & \multirow[t]{2}{*}{$n$} & \multicolumn{2}{|c|}{ Clinical Cure } & \multicolumn{2}{|c|}{ Death } \\
\hline & & $n$ & $\overline{\text { rate }(\%)}$ & $n$ & rate $(\%)$ \\
\hline Non-anticoagulation & 28 & 9 & 32.1 & 19 & 67.9 \\
\hline Anticoagulation & 75 & 49 & 65.3 & 26 & 34.7 \\
\hline Anticoagulation + TIPS & 14 & 9 & 64.3 & 5 & 35.7 \\
\hline
\end{tabular}


In the present study, 5 year survival was $57 \%$, which is higher than those reported from Western countries [20$22]$. This difference can be explained by the severe underlying haematological disorders associated with stem cell transplantation in HVOD patients in those studies; development of HVOD following pre-treatment for transplantation is more serious and can easily lead to liver and multiorgan failure and death. In contrast, the patients with Gynura segetum-induced HVOD do not necessarily have serious underlying diseases. Moreover, $70 \%$ of the current study cohort were treated with anticoagulants, which were reported to contribute to improved HVOD prognosis [23].

The aim of the present study was to assess prognostic determinants of survival in HVOD patients. We identified three important factors that were independently associated with survival: serum bilirubin, serum albumin and encephalopathy. Child-Pugh is a well-known and widely used classification of liver disease. These three prognostic factors identified in the current study are included in the ChildPugh staging system. Conversely, ascites and prothrombin time did not exhibit a significant impact on survival.

Unlike other common causes of HVOD including high-dose chemotherapy before HSCT, Gynura segetu$m$-induced HVOD is unpredictable. It is critical to avoid further contact with the suspicious toxin as soon as possible once symptoms appear or when a definitive diagnosis is reached. Currently, there are no effective therapies for HVOD, and supportive care remains the cornerstone of management, including restriction of water and sodium intake, albumin infusion, abdominal paracentesis and diuretics. Defibrotide is a promising agent with anti-ischaemic, anti-inflammatory and antithrombotic activity [24]; however, the results of defibrotide therapy are conflicting and are not shown to be cost-effective [25]. Our results suggested that anticoagulation therapy significantly increased the cure rate of HVOD, compared with the symptomatic treatment. TIPS is used to relieve portal hypertension and refractory ascites; however, many studies reported that its efficacy in HVOD was poor [26, 27]. Our study also revealed that the cure rate of anticoagulation therapy was comparable with that of anticoagulation therapy in combination with TIPS, with no statistical difference between the two groups, which might be due to the small number of patients receiving the combination treatment. Therefore, future studies with larger cohort sizes are necessary to assess the efficacy and outcomes of combination treatment with anticoagulation therapy and TIPS.

\section{Conclusions}

Major prognostic factors for Gynura segetum-induced HVOD were the presence of hepatic encephalopathy and serum bilirubin and albumin levels. Compared with symptomatic treatment, anticoagulation therapy was associated with a significant increased cure rate, but TIPS treatment had no additional effect on improving the cure rate. No uniformly effective treatments are available for HVOD, and the mortality remains high; therefore, prevention of the potent toxicity of Gynura segetum is critical. Future studies are necessary to investigate the mechanisms of HVOD to improve the survival rate.

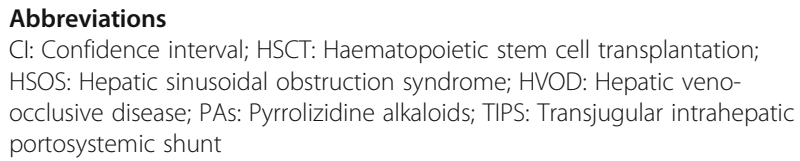

\section{Author' contributions}

YW participated in the collection and analysis of data and wrote the manuscript. DQ and YL participated in the data collection and analysis. FX participated in conception and oversight of the study, supervision, data analysis and manuscript editing. All authors read and approved the final version of the manuscript.

\section{Funding}

Not applicable

\section{Availability of data and materials}

The data set analysed in the study cannot be made available to the public because patients' privacy must be protected. However, the raw data are available from the corresponding author upon reasonable request.

\section{Ethics approval and consent to participate}

The study was approved by the Ethics Committee of the First Affiliated Hospital of Zhengzhou University (No. 20130802GS-9). Written informed consent to participate was obtained from all patients.

Consent for publication

Not applicable

\section{Competing interests}

The authors declare that they have no competing interest.

\section{Publisher's Note}

Springer Nature remains neutral with regard to jurisdictional claims in published maps and institutional affiliations.

\section{Author details}

${ }^{1}$ Department of Gastroenterology, The First Affiliated Hospital of Zhengzhou University, 1 Jianshe Donglu, Zhengzhou 450052, Henan, China. ²Department of Zhengzhou Center for Disease Control and Prevention, Zhengzhou, China.

Received: 13 March 2018 Accepted: 2 October 2018

Published online: 26 October 2018

\section{References}

1. Cacchione A, LeMaitre A, Couanet DV, Benhamou E, Amoroso L, Simonnard N, Hartmann O. Risk factors for hepatic veno-occlusive disease: a retrospective unicentric study in 116 children autografted after a high-dose BU-thiotepa regimen. Bone Marrow Transplant. 2008;42(7):449-54.

2. Mohty M, Malard F, Abecassis M, Aerts E, Alaskar AS, Aljurf M, Arat M, Bader $P$, Baron F, Bazarbachi A, et al. Sinusoidal obstruction syndrome/venoocclusive disease: current situation and perspectives-a position statement from the European Society for Blood and Marrow Transplantation (EBMT). Bone Marrow Transplant. 2015;50(6):781-9.

3. Gozdzik J, Krasowska-Kwiecien A, Wedrychowicz A. sinusoidal obstruction disease (SOS), previous hepatic venoocclusive disease (VOD)--still serious complication after hematopoietic stem cell transplantation. Przegl Lek. 2008; 65(4):203-8

4. Cheng Y, Liang D, Zhan Y. Morphological and histological studies of herba sedum aizoon. Zhong Yao Cai. 2001;24(5):330-2. 
5. Lin G, Wang JY, Li N, Li M, Gao H, Ji Y, Zhang F, Wang H, Zhou Y, Ye Y, et al. Hepatic sinusoidal obstruction syndrome associated with consumption of Gynura segetum. J Hepatol. 2011;54(4):666-73.

6. Kan X, Ye J, Rong X, Lu Z, Li X, Wang Y, Yang L, Xu K, Song Y, Hou X. Diagnostic performance of contrast-enhanced $C T$ in pyrrolizidine alkaloidsinduced hepatic sinusoidal obstructive syndrome. Sci Rep. 2016;6:37998.

7. Li X, Yang X, Xu D, Li Q, Kong X, Lu Z, Bai T, Xu K, Ye J, Song Y. Magnetic resonance imaging findings in patients with pyrrolizidine alkaloid-induced hepatic sinusoidal obstruction syndrome. Clin Gastroenterol Hepatol. 2017; 15(6):955-7.

8. Shao H, Chen HZ, Zhu JS, Ruan B, Zhang ZQ, Lin X, Gan MF. Computed tomography findings of hepatic veno-occlusive disease caused by Sedum aizoon with histopathological correlation. Braz J Med Biol Res. 2015;48(12):1145-50.

9. Boyer TD, Haskal ZJ, American Association for the Study of liver D. The role of transjugular intrahepatic portosystemic shunt in the management of portal hypertension. Hepatology. 2005:41 (2):386-400.

10. Chen Z, Huo JR. Hepatic veno-occlusive disease associated with toxicity of pyrrolizidine alkaloids in herbal preparations. Neth J Med. 2010;68(6):252-60.

11. Zhou H, Wang YX, Lou HY, Xu XJ, Zhang MM. Hepatic sinusoidal obstruction syndrome caused by herbal medicine: CT and MRI features. Korean J Radiol. 2014;15(2):218-25.

12. Gao H, Li N, Wang JY, Zhang SC, Lin G. Definitive diagnosis of hepatic sinusoidal obstruction syndrome induced by pyrrolizidine alkaloids. J Dig Dis. 2012;13(1):33-9.

13. Gao H, Ruan JQ, Chen J, Li N, Ke CQ, Ye Y, Lin G, Wang JY. Blood pyrroleprotein adducts as a diagnostic and prognostic index in pyrrolizidine alkaloid-hepatic sinusoidal obstruction syndrome. Drug Design Dev Ther. 2015:9:4861-8.

14. McDonald GB, Sharma P, Matthews DE, Shulman HM, Thomas ED. Venocclusive disease of the liver after bone marrow transplantation: diagnosis, incidence, and predisposing factors. Hepatology. 1984;4(1):116-22.

15. Bayraktar UD, Seren S, Bayraktar Y. Hepatic venous outflow obstruction: three similar syndromes. World I Gastroenterol. 2007;13(13):1912-27.

16. Kumar S, DeLeve LD, Kamath PS, Tefferi A. Hepatic veno-occlusive disease (sinusoidal obstruction syndrome) after hematopoietic stem cell transplantation. Mayo Clin Proc. 2003;78(5):589-98.

17. Fan CQ, Crawford JM. Sinusoidal obstruction syndrome (hepatic venoocclusive disease). J Clin Exp Hepatol. 2014;4(4):332-46.

18. Wang X, Qi X, Guo X. Tusanqi-related sinusoidal obstruction syndrome in China: a systematic review of the literatures. Medicine. 2015;94(23):e942.

19. Wang JY, Gao H. Tusanqi and hepatic sinusoidal obstruction syndrome. J Dig Dis. 2014;15(3):105-7.

20. Coppell JA, Richardson PG, Soiffer R, Martin PL, Kernan NA, Chen A, Guinan E, Vogelsang G, Krishnan A, Giralt S, et al. Hepatic veno-occlusive disease following stem cell transplantation: incidence, clinical course, and outcome. Biol Blood Marrow Transpl. 2010;16(2):157-68.

21. Richardson PG, Riches ML, Kernan NA, Brochstein JA, Mineishi S, Termuhlen AM, Arai S, Grupp SA, Guinan EC, Martin PL, et al. Phase 3 trial of defibrotide for the treatment of severe veno-occlusive disease and multi-organ failure. Blood. 2016;127(13):1656-65.

22. Richardson PG, Smith AR, Triplett BM, Kernan NA, Grupp SA, Antin JH, Lehmann L, Shore T, lacobelli M, Miloslavsky M, et al. Defibrotide for patients with hepatic Veno-occlusive disease/sinusoidal obstruction syndrome: interim results from a treatment IND study. Biol Blood Marrow Transpl. 2017;23(6):997-1004.

23. Yang D, Yang J, Shi D, Deng R, Yan B. Scoparone potentiates transactivation of the bile salt export pump gene and this effect is enhanced by cytochrome P450 metabolism but abolished by a PKC inhibitor. Br J Pharmacol. 2011;164(5):1547-57.

24. Palomo M, Mir E, Rovira M, Escolar G, Carreras E, Diaz-Ricart M. What is going on between defibrotide and endothelial cells? Snapshots reveal the hot spots of their romance. Blood. 2016;127(13):1719-27.

25. Aziz MT, Kakadiya PP, Kush SM, Weigel K, Lowe DK. Defibrotide: an oligonucleotide for sinusoidal obstruction syndrome. Ann Pharmacother. 2017. https://doi.org/10.1177/1060028017732586.

26. Azoulay D, Castaing D, Lemoine A, Hargreaves GM, Bismuth H. Transjugular intrahepatic portosystemic shunt (TIPS) for severe veno-occlusive disease of the liver following bone marrow transplantation. Bone Marrow Transplant. 2000;25(9):987-92

27. Rajvanshi P, McDonald GB. Expanding the use of transjugular intrahepatic portosystemic shunts for veno-occlusive disease. Liver Transpl. 2001;7(2): 154-7.

\section{Ready to submit your research? Choose BMC and benefit from:}

- fast, convenient online submission

- thorough peer review by experienced researchers in your field

- rapid publication on acceptance

- support for research data, including large and complex data types

- gold Open Access which fosters wider collaboration and increased citations

- maximum visibility for your research: over $100 \mathrm{M}$ website views per year

At BMC, research is always in progress.

Learn more biomedcentral.com/submissions 